$\mathrm{DE}$

M E D I C I N A

T R O P I C A L

$\mathrm{DE}$

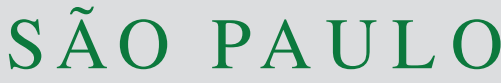

JOURNAL OF THE SÃO PAULO INSTITUTE OF TROPICAL MEDICINE

${ }^{1}$ Hospital General "Dr. Manuel Gea González", Departamento de Ecología de Agentes Patógenos, Ciudad de México, México

${ }^{2}$ Hospital General "Dr. Manuel

Gea González", Departamento de Dermatopatología, Ciudad de México, México

3Universidad Nacional Autónoma de México, Facultad de Medicina, Ciudad de México, México

${ }^{4}$ Universidad Nacional Autónoma de México, Clínica de Onco-Dermatología, Ciudad de México, México

${ }^{5}$ Instituto Politécnico Nacional, Escuela Nacional de Ciencias Biológicas, Laboratorio de Entomología, Ciudad de México, México

${ }^{6}$ Hospital General "Dr. Manuel Gea González", Departamento de Biología Molecular e Histocompatibilidad, Ciudad de México, México

Correspondence to: Mirza Romero Valdovinos

Hospital General "Dr. Manuel Gea Gonzalez", Departamento de Biologia Molecular e Histocompatibilidad, Calzada de Tlalpan, 4800, Tlalpan, 14080, Ciudad de Mexico, Mexico

Tel: +525540003000 ext. 6100

E-mail: mirzagrv@gmail.com

Received: 1 July 2019

Accepted: 5 August 2019

\section{Myiasis caused by Dermatobia hominis in Mexico: morphological and molecular identification using the cytochrome oxidase I gene}

Fernando Martínez-Hernández¹, Maria Elisa Vega-Memije², Guiehdani Villalobos ${ }^{1}$, Diego Perez-Rojas ${ }^{3}$, Daniel Asz-Sigall ${ }^{4}$, Nancy Rivas ${ }^{5}$, Ricardo Alejandre $^{5}$, Pablo Maravilla ${ }^{(1)}$, Mirza Romero Valdovinos ${ }^{(06}$

\section{ABSTRACT}

Myiasis caused by Dermatobia hominis, the human botfly, is frequent in the Americas, however, scarce morphological and molecular information exist regarding this dipteran. We describe three cases in urban areas of Mexico were $D$. hominis is not endemic. Morphological and genetic identification were performed using the cytochrome oxidase I as a molecular marker. The mitochondrial cytochrome oxidase I gene is useful for inferring the genetic divergence of $D$. hominis.

KEYWORDS: Dermatobia hominis. Myiasis. Cytochrome oxidase I (coxI). Mitochondrial genes. Molecular markers.

\section{INTRODUCTION}

In the Americas, myiasis is caused by different genera of dipterans, such as Cordylobia, Chrysomya, Cuterebra and Oestrus. Larvae of these dipterans feed on the host's living or dead tissues, body fluids, or ingested food can cause a broad range of symptoms depending on the infestation site and the relationship between the larvae and the host ${ }^{1-5}$. The human botfly, Dermatobia hominis (Linnaeus, 1781), causes obligatory myiasis and this parasite depends on the host to complete its life cycle. Although furuncular myiasis is a common disease caused by this fly, vaginal, palpebral, ocular, rhinal and cerebral myiasis can be fatal ${ }^{5,6}$. Cases in people traveling to developing countries and cases in non-endemic countries are becoming more common ${ }^{4,5}$. D. hominis is distributed from Mexico to Paraguay and in Northeast Argentina ${ }^{1,3}$. In Mexico, endemic areas include territories in the Southern region, specifically Yucatan and Quintana Roo States, where several cases have been documented ${ }^{7,8}$. However, in regions in which $D$. hominis is uncommon, infestations can be misidentified and incorrectly treated ${ }^{4}$. Here, we reported three cases: one imported case from Brazil and two autochthonous cases of myiasis caused by $D$. hominis in Mexico. In addition, morphological and molecular identification was performed using the cytochrome oxidase I gene.

\section{CASE DESCRIPTION}

A 50-year-old male resident of Quintana Roo, Mexico, with a personal history of type 2 diabetes controlled by metformin presented with dermatitis located in the lateral and posterior region of the left heel characterized by two furuncular lesions 
(Figures 1A and 1B), with a two-month history of pain, paresthesia and bloody serous secretion. He had returned from a trip to the Amazon region (Brazil) where he had been bitten by different insects. Several oral antibiotics were administered to the patient without improvement. Under anesthesia, the lesion was irrigated with saline solution, and two maggots that measuring $17 \mathrm{~mm}$ wide and $21 \mathrm{~mm}$ long with a diameter of approximately $5 \mathrm{~mm}$ were observed (Figure 1D). They showed growth and movement. According to the records, the clinical diagnosis was myiasis.
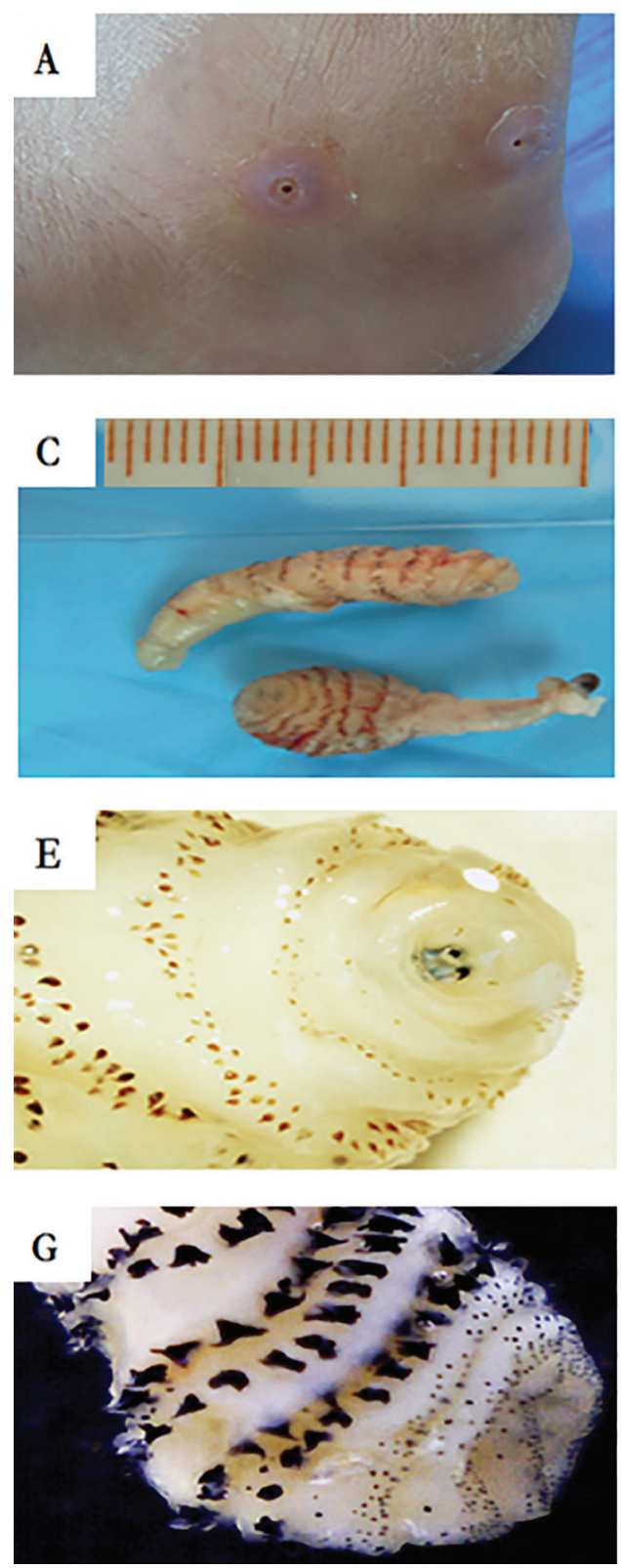

A 40-year-old female living in Mexico City, without significant pathological findings related to the studied condition, showed a dermatosis (Figure 1C) characterized by an indurated erythematous-colored plaque with a central bloody serous crust on the right leg after a trip to the State of Campeche. The patient had minor pain and did not report a significant pathological history. The same medical staff member extracted a maggot measuring 20 $\mathrm{mm}$ long (Figures $1 \mathrm{E}$ and $\mathrm{F}$ ) by using mechanical pressure and presented it for medical examination. Again, the diagnosis was myiasis. Subsequently, a scab and a residual
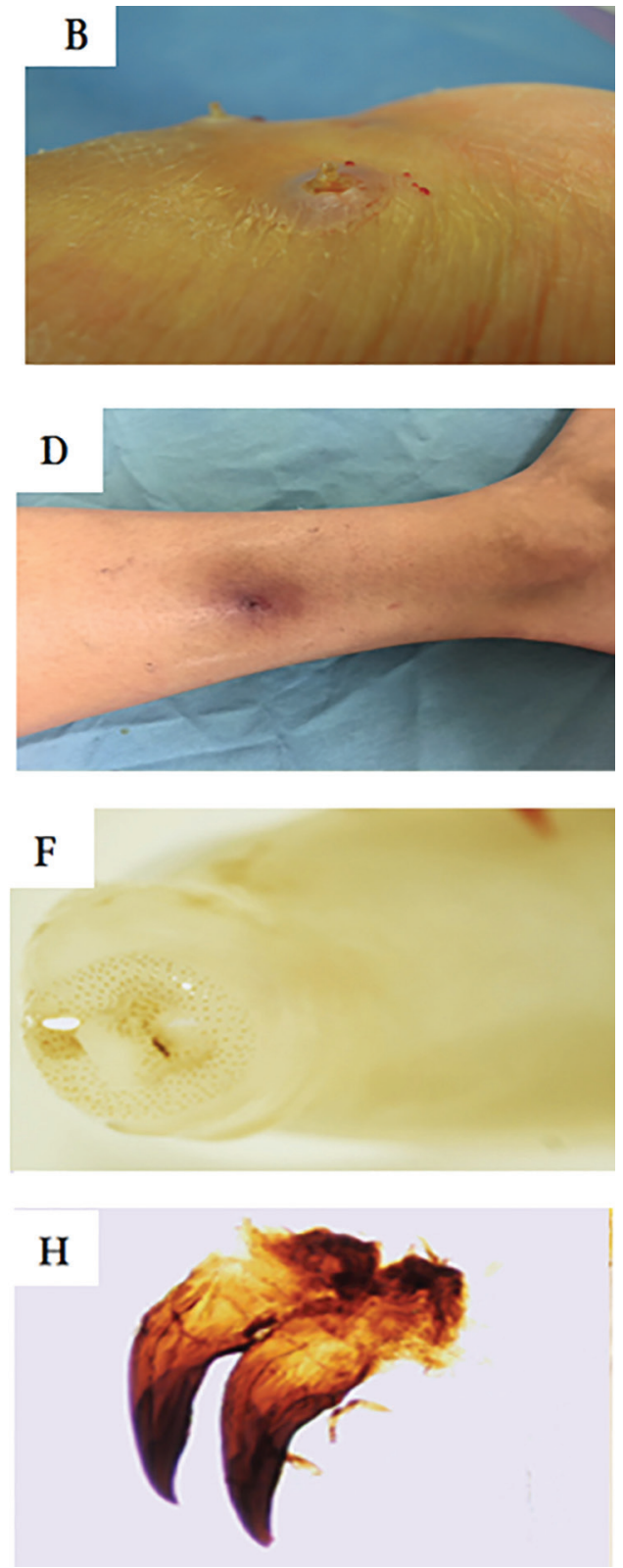

Figure 1 - A) Furuncular lesions in the lateral region of the left heel (case 1); B) Residual injuries caused by maggots of $D$. hominis after anesthetic infusion of the lesion (case 1); C) Maggots from ulcers (case 1); D) Left leg injury (case 2); E) Anteroposterior section of some of the larvae analyzed; F) Posterior section of some of the larvae analyzed; G) Presence of spicules in the larvae analyzed; H) Larval maxillar hook. 
hyperchromic scar formed in the area, and the patient healed without specific treatment.

A 44-year-old male resident of Mexico City, with no significant personal history of disease, presented to the dermatologist with two furuncular lesions located on the lower back region that developed approximately one month after a trip to Chiapas State. The patient indicated inconspicuous pain. After a medical examination and oral treatment with clindamycin without improvement, surgery was indicated and removed two maggots (Figure 1G), under anesthesia, that were $9 \mathrm{~mm}$ wide and $12 \mathrm{~mm}$ long and approximately $4 \mathrm{~mm}$ in diameter. The clinical diagnosis was myiasis. Subsequently, a scab and a residual hyperchromic scar formed in the area, and the wound healed without specific treatment.

\section{Morphological and molecular cytochrome oxidase I identification}

Larvae extracted larvae from the patients were morphologically studied and identified according to Villalobos et al. ${ }^{4}$. The maggots were cylindrical shaped and yellowish-white colored, with a size of 9 to $21 \mathrm{~mm}$ in length and approximately 5 to $7 \mathrm{~mm}$ in wide. Backward projecting spines that encircled the thorax and cephalic region were observed (Figures 1D, 1E, 1F and 1G). The maggots were identified as D. hominis; two of them were first instars and three were second instars. In the anterior portion where the oral opening is located, two oral or maxillary hooks were present; they were strongly sclerosed and had dark pigments (Figure 1H). The posterior portion of the maggot was fixed, and the presence of two respiratory stigmas or respiratory spiracles were observed, each of them presenting three eyelets or openings with spiracles and trabeculae. The peritreme was not evident. Behind the stigmas, in the inner portion of the exoskeleton, two scaffold-like structures were present. These structures were part of the tracheal system of the maggot.

Genomic DNA was extracted from the larvae using the quick-DNA extraction kit (ZYMO Research Corporation, CA, USA). A novel primer set, TdCO1int 5'-CTTCATTCTTTGACCCAGCAGGWGG-3 and TdCO1r 5'- TGAGTAT GARTGTTCTGCWGGNGG-3', was used to amplify approximately 857 base pair (bp) from the cytochrome oxidase I (coxI) gene. PCR cycling conditions were, as follows: initial denaturation at $95{ }^{\circ} \mathrm{C}$ for $10 \mathrm{~min}$; followed by 38 cycles of denaturation at $95^{\circ} \mathrm{C}$ for $30 \mathrm{~s}$, annealing at $56^{\circ} \mathrm{C}$ for $30 \mathrm{~s}$ and extension at $72{ }^{\circ} \mathrm{C}$ for $30 \mathrm{~s}$ ending with a final extension at $72{ }^{\circ} \mathrm{C}$ for $7 \mathrm{~min}$.

The amplified sequences were submitted to the GenBank database (MK593540-2). Multiple alignments were performed using the MEGA software version $7.0^{9}$. The bestfit model of nucleotide substitution was determined using the Akaike information criterion in the Modeltest version 3.7; the GTR+G+I model was used ${ }^{10}$. Phylogenetic reconstruction was performed according to Villalobos et al. ${ }^{4}$.

The phylogenetic inference showed a clear separation of different species by clades with high values of posterior probability support. The sequences of $D$. hominis obtained in the present study (MK593540-2) were clustered with other sequences belonging to the same species (AY463155, AY507157 and NC 006378), and grouped near the clade of species belonging to the genera Cuterebra. In particular, all the individuals of Dermatobia showed genetic differences that suggested a possible association with their geographical locations (Figure 2).

\section{DISCUSSION}

Human myiasis caused by $D$. hominis is endemic from the Southern region of Mexico to Paraguay and Northeast Argentina. However, cases have already been reported in nonindigenous people who traveled to endemic zones ${ }^{11}$. Although Mexico has autochthonous cases, imported cases have also been documented ${ }^{12}$. Cases of myiasis acquired in South America and other regions in Mexico were reported here. Regarding the two cases acquire in Mexico, both were diagnosed in regions of the country where it is uncommon to find reports of myiasis. For this reason, it was difficult to properly identify the maggots. Additionally, maggots were morphologically identified. The spine structures developed over 30 to 60 days depending on the host infection time ${ }^{12,13}$. The presence of distinctive spines on the terminal body segments of the larvae was useful to identify this species. The final characterization showed maggots in the second and third instars that are commonly found in infected people due to the timeline of infection. A detailed morphological identification of the maggots has been described.

Although the gold standard for the identification of D. hominis is the morphological analysis, the inclusion of molecular techniques is relevant because these tools have high sensitivity and specificity for the diagnosis of several parasitic infections. In addition, some molecular markers support new taxonomic classifications and are useful in assessing the genetic variation of pathogens. In particular, the cytochrome oxidase I gene has shown to be a sensitive molecular marker to discriminate different species and genera of insects, dividing them into specific clades and identifying high genetic diversity. In the case of D. hominis, there are few sequences deposited in GenBank, and amplification of the barcoding region is troublesome ${ }^{14}$. The primers selected in this study contained only $88 \mathrm{bp}$ of 


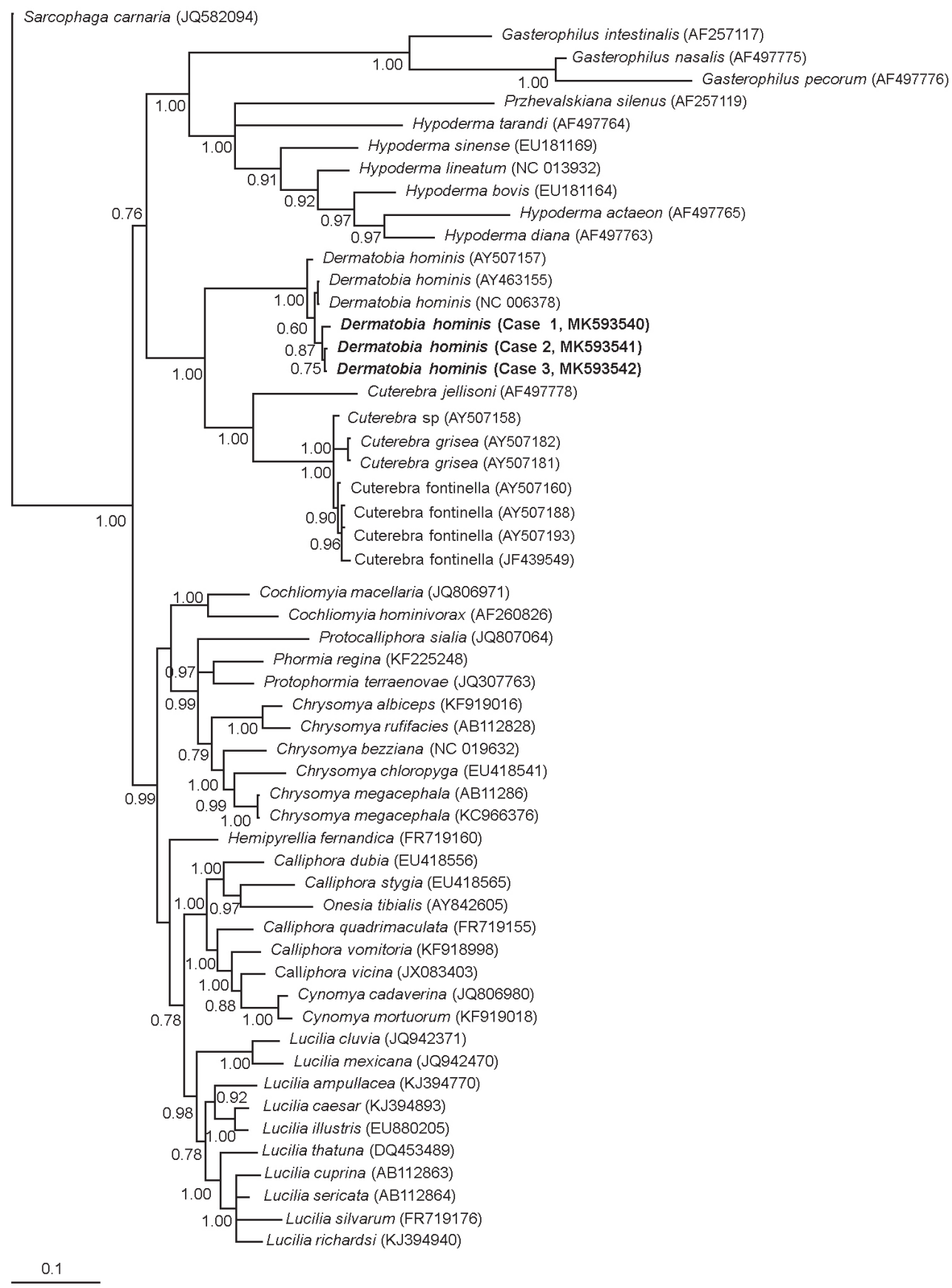

Figure 2 - The Bayesian phylogenetic tree constructed with cytochrome oxidase I (coxl) sequences from Dipteran species causing myiasis in the world. Numbers on branches indicate posterior probability values and different shades of gray indicate the taxonomic family to which each species belongs. Data sequences were obtained from the GenBank database. The samples highlighted in bold represent the sequences obtained in present study.

barcoding, however, our goal was to cover the major gene fragment and compare this fragment to the homologous region of Dermatobia with the highest number of sequences available on GenBank. However, more detailed studies to identify $D$. hominis variations should be conducted. Finally, tourists traveling to endemic areas of myiasis should be instructed to use repellent and clothing that covers all skin exposed to insect bites.

\section{CONCLUSIONS}

Although Dermatobia hominis is uncommon in Mexico City, we identified three cases. Mitochondrial markers such as coxI can differentiate the species and genera. This classification has been troublesome with other markers, such as ITS $^{15}$. 


\section{AUTHORS' CONTRIBUTIONS}

FM-H and GV performed the PCR, purification of amplicons, and sequencing assays. MEV-M, DA-S, and DP-R were responsible for clinical selection and attention to patients. NR and RA were responsible for the morphological identification of maggots.MR-V, MP, and FM-H contributed with critical comments. All authors participated during the discussion and writing of the manuscript and approved its final version.

\section{CONFLICT OF INTERESTS}

The authors declare that they have no competing interests.

\section{ETHICS APPROVAL}

Written informed consent was obtained from each participant; all procedures were in accordance with the Regulations of the General Health Law in the Field of Health Research in Mexico: NOM-012-SSA3-2012, Title II, Chapter II, General Dispositions.

\section{REFERENCES}

1. Denion E, Dalens PH, Couppié P, Aznar C, Sainte-Marie D, Carme B, et al. External ophthalmomyiasis caused by Dermatobia hominis: a retrospective study of nine cases and a review of the literature. Acta Ophtalmol Scand. 2004;82:576-84.

2. Francesconi F, Lupi O. Myiasis. Clin Microbiol Rev. 2012;25:79105.

3. Vijay K, Kalapos P, Makkar A, Engbrecht B, Agarwal A. Human botfly (Dermatobia hominis) larva in a child's scalp mimicking osteomielitis. Emerg Radiol. 2013;20:81-3.

4. Villalobos G, Vega-Memije ME, Maravilla P, Martinez-Hernandez F. Myiasis caused by Dermatobia hominis: countries with increased risk for travelers going to neotropic areas. Int $\mathbf{J}$ Dermatol. 2016;55:1060-8.
5. Fernandes FF, Chiarini-Garcia H, Linardi PM. Scanning electron microscopy studies of sensilla and other structures of adult Dermatobia hominis (L. Jr., 1781) (Diptera: Cuterebridae). J Med Entomol. 2004;41:552-60.

6. University of Florida. Featured creatures: entomology \& nematology. [cited 2019 Aug 6], Available from: http:// entomology.ifas.ufl.edu/creatures

7. Quintanilla-Cedillo MR, León-Ureña H, Contreras-Ruiz J, Arenas $\mathrm{R}$. The value of Doppler ultrasound in diagnosis in 25 cases of furunculoid myiasis. Int J Dermatol. 2005;44:34-7.

8. Laviada AF, Zavala Velázquez J, Pench Canul T, Reyes Pérez A. Miasis en Yucatan. Dermatol Rev Mex. 1976;20:121-31.

9. Kumar S, Stecher G, Tamura K. MEGA7: Molecular Evolutionary Genetics Analysis Version 7.0 for bigger datasets. Mol Biol Evol. 2016;33:1870-4.

10. Posada D, Crandall KA. MODELTEST: testing the model of DNA substitution. Bioinformatics. 1998;14:817-8.

11. Contreras-Ruiz J, Arenas-Guzmán J, Vega-Memije ME, CastilloDíaz M. Miasis furunculoide por Dermatobia hominis: un caso importado de Costa Rica al Distrito Federal. Gac Med Mex. 2004;140:81-3.

12. Varani S, Tassinari D, Elleri D, Forti S, Bernardi F, Lima M, et al. A case of furuncular myiasis associated with systemic inflammation. Parasitol Int. 2007;56:330-3.

13. Alcalá D, Yánez S. Miasis furuncular causada por Dermatobia hominis. Rev Cent Dermatol Pascua. 2006;15:23-5.

14. Folmer O, Black M, Hoeh W, Lutz R, Vrijenhoek R. DNA primers for amplification of mitochondrial cytochrome c oxidase subunit I from diverse metazoan invertebrates. Mol Mar Biol Biotechnol. 1994;3:294-9.

15. Toussaint-Cairo S, Woroszylski-Yoselevitz A, Vega-Memije ME, Villalobos G, Rivas N, Alejandre-Aguilar R, et al. Imported and autochthonous cases of myiasis caused by Dermatobia hominis: taxonomic identification using the internal transcribed spacer region. Am J Trop Med Hyg. 2018;99:940-4. 